\title{
Pits in Metals Caused by Collision With Liquid Drops and Rigid Steel Spheres
}

\author{
Olive G. Engel
}

\author{
(September 24, 1959)
}

\begin{abstract}
A pit-depth-versus-velocity equation developed earlier was tested further with experimental data obtained using target plates of electrolytic tough pitch copper, 1100-0 aluminum, and 2024-O aluminum, the static strength properties of which were measured by testing tensile specimens. The projectiles used to produce the pits were mercury drops, waterdrops, and steel spheres. It was found that the numerical constants in the equation for projectiles that flow during and as a result of the collision are different from those for projectiles that do not flow (hardened steel spheres). Curves calculated using the equation were found to be in acceptable agreement with experimental pit-depth-versus-velocity data for collisions of the indicated projectiles with target plates of the three metals used with the exception of the case of steel-sphere impingement against 2024-O aluminum alloy. In this case work-hardening of the target metal seems to foster a mode of pit formation that was not considered in the development of the pit-depth-versus-velocity equation.
\end{abstract}

\section{Introduction}

Collisions between liquids and solids in all of the possible projectile-target combinations in which they can occur have been topics for research. Some of these are: solid-against-solid collisions (artillery experiments), solid-against-liquid collisions (waterentry problems), liquid-against-solid collisions (highspeed rain-erosion research), and liquid-againstliquid collisions (impact of solids at meteor velocities). Work has been done at the National Bureau of Standards toward developing an equation that will give pit depth as a function of impingement velocity for collisions of target plates of the soft and medium hard metals with drops of liquids [1]. ${ }^{1}$

The model on which the equation is based is the movement of the core of metal of the target plate immediately under the collision area with respect to the remainder of the plate. In order that the core of metal through the target plate under the collision area may be free to move, the side of the plate opposite to that on which the collision occurs must be a free surface. In addition to this condition on the target plate, it must not be so thin that it bends as a whole under the collision, or so thick that the spread of the compressional wave that passes through it as a result of the collision is appreciable.

In the development of this pit-depth-versusvelocity equation, such characteristic fluid-flow parameters as the Weber number and the Revnolds number were neglected. The equation should, therefore, apply equally well to pits caused by collisions of solid spheres with target plates of the soft and medium hard metals.

In the case of collisions of solid-sphere projectiles that flow like a liquid drop during and as a result of the collision, the equation should apply without modification even of the numerical constants. It

\footnotetext{
1 Figures in brackets indicate the literature references at the end of this paper.
}

has been found that the equation does produce curves that fit pit-depth-versus-velocity data for high-speed collisions of soft ductile metal spheres against targets of the same metals [1].

For the case of collisions of hardened steel spheres, the numerical constants in the equation will be different. These spheres do not flow during the collision; none of the collision energy is lost in the flow of the projectile and, therefore, a larger amount of it is used in forming the pit.

Pit-depth-versus-velocity data ${ }^{2}$ for high-speed collision of liquid drops with metal plates were used to evaluate the numerical constants in the equation and to test the equation. These data were of a preliminary nature. The yield strength and the speed of sound of the metals used for the target plates were not determined by experiment. The speed of sound in this case is the speed of irrotational waves in an infinite medium.

It is important to know the static yield strength of the target metal. Although it is the dynamic yield strength that must be used in the equation, in most cases the dynamic yield strength may be expected to vary in the same direction that the static yield strength varies for different heattreatment states of a given metal. Different sets of pit-depth-versus-velocity data will not, in general, be comparable unless the static yield strength of the metal target plates that are used is essentially the same. Furthermore, the static yield strength can be used to calculate the dynamic yield strength in the case of the duralumins [2] and closely related aluminum alloys.

The work described in this paper is an effort to test the equation further by determining the depth of pits that result from impingement of waterdrops, mercury drops, and rigid steel spheres against target

2 These data were obtained at Convair, Division of General Dynamies Corp. in San Diego, Calif. See reference [1]. 
plates of $1100-\mathrm{O}$ aluminum, 2024-O aluminum, and annealed electrolytic tough pitch copper, the static yield strengths of which have been determined by experiment. The work described was conducted under the sponsorship of the Materials Laboratory, Directorate of Laboratories, Wright Air Development Center. The experimental work was done at Convair, Division of General Dynamics Corp., in San Diego, Calif., and at the U.S. Naval Research Laboratory in Washington, D.C.

\section{Materials}

\subsection{Preparation of the Target Plates}

Plates of the metals were obtained in $2.5-\mathrm{cm}$ (1in.) thickness so that $15.2-$ by -15.2 -cm (6- by -6 -in.) target plates cut from them for use in experiments involving impingement of $0.5556-\mathrm{cm}-(7 / 32-\mathrm{in} .-)$, $0.7938-\mathrm{cm}-(5 / 16-$ in.-), and $1.270-\mathrm{cm}-$ (1/2-in.-) diam steel spheres, would be approximately 2 to 4.5 sphere diameters thick. Tensile specimens for determining the static yield strength and small $0.317-\mathrm{cm}-\left(\frac{1}{8}-\mathrm{in} .-\right)$ thick target plates for use in experiments involving collision with $0.1-\mathrm{cm}$ and $0.2-\mathrm{cm}$ drops of mercury and water were machined from some of this material.

The $1100-\mathrm{O}$ aluminum was obtained from the Davenport Works of the Aluminum Co. of America in Riverdale, Iowa. The material was furnished in mill finish and was as scratch-free as was commercially feasible. For the annealing process the objects were placed in the furnace while it was cold. The furnace temperature was then brought up to $343^{\circ} \mathrm{C}\left(650^{\circ} \mathrm{F}\right)$ and was held at $343^{\circ} \mathrm{C}\left(650^{\circ} \mathrm{F}\right)$ for $4.5 \mathrm{hr}$ in the case of the large target plates and the tensile specimens and for about $2 \mathrm{hr}$ in the case of the small target plates. The furnace was then turned off and the objects were allowed to cool with the furnace. The tensile specimens were suspended in the vertical position during the annealing process to prevent sagging.

The 2024-O aluminum was obtained as 2024-T4 aluminum at the U.S. Naval Research Laboratory in Washington, D.C. For the annealing process the tensile specimens and the target plates of this aluminum alloy were put into the furnace after it had been raised to a temperature of $399^{\circ} \mathrm{C}\left(750^{\circ} \mathrm{F}\right)$. They were heated at $399^{\circ} \mathrm{C}\left(750^{\circ} \mathrm{F}\right)$ for $4 \mathrm{hr}$, cooled to $166^{\circ} \mathrm{C}\left(350^{\circ} \mathrm{F}\right)$ at a rate of $25.5^{\circ} \mathrm{C}\left(46^{\circ} \mathrm{F}\right)$ per hour, and then removed from the furnace.

The electrolytic tough pitch copper was obtained from the American Brass Co. For annealing, the objects were placed in the furnace after it had attained a temperature of $427^{\circ} \mathrm{C}\left(800^{\circ} \mathrm{F}\right)$. The large target plates were kept in the hot furnace for approximately $1 \mathrm{hr}$, the small target plates for about $40 \mathrm{~min}$, and the tensile specimens for about $30 \mathrm{~min}$. The objects were in each case removed from the furnace at the end of the specified time and were air cooled. The copper oxide that formed was removed from the target plates by pickling in dilute acid and by gentle abrasion.

\subsection{Static Tensile Properties of the Metals}

The tensile specimens were standard ASTM test specimens having $1.283-\mathrm{cm}(0.505$-in.) diameter in accordance with ASTM designation E 8-54 T. They were tested in a standard testing machine in the NBS Engineering Mechanics Section using autographic recording equipment. The data obtained were yield strength (0.2 percent offset), tensile strength, and elongation in $5.1 \mathrm{~cm} \mathrm{(2} \mathrm{in.).} \mathrm{The} \mathrm{test}$ results are given in table 1.

TABLe 1. Static tensile properties of the metals

\begin{tabular}{|c|c|c|c|c|c|}
\hline \multirow{2}{*}{$\begin{array}{c}\text { Metal } \\
1100-\mathrm{O} \text { aluminum } \ldots \\
1100-\mathrm{O} \text { aluminum. } . . . . . . . .\end{array}$} & \multicolumn{2}{|c|}{ Yield strength } & \multicolumn{2}{|c|}{ Tensile strength } & \multirow{2}{*}{$\begin{array}{r}\begin{array}{c}\text { Elonga- } \\
\text { tion }\end{array} \\
\begin{array}{r}41.0 \\
41.5\end{array}\end{array}$} \\
\hline & $\begin{array}{r}10^{8} \mathrm{~d} / \mathrm{cm} \mathrm{cm}^{2} \\
1.83 \\
1.79\end{array}$ & $\begin{array}{l}\text { psi } \\
2,650 \\
2,600\end{array}$ & $\begin{array}{r}10^{8} \mathrm{~d} / \mathrm{cm}^{2} \\
7.83 \\
7.65\end{array}$ & $\begin{array}{c}p s i \\
11,350 \\
11,100\end{array}$ & \\
\hline $\begin{array}{l}2024-\mathrm{O} \text { aluminum. } \\
2024-\mathrm{O} \text { aluminum } \\
2024-\mathrm{O} \text { aluminum } \\
2024-\mathrm{O} \text { aluminum }\end{array}$ & $\begin{array}{l}8.69 \\
8.76 \\
8.69 \\
8.69\end{array}$ & $\begin{array}{l}12,600 \\
12,700 \\
12,600 \\
12,600\end{array}$ & $\begin{array}{l}19.6 \\
20.0 \\
20.7 \\
20.9\end{array}$ & $\begin{array}{l}28,400 \\
29,000 \\
30,000 \\
30,300\end{array}$ & $\begin{array}{l}17.5 \\
17.5 \\
18.0 \\
18.5\end{array}$ \\
\hline $\begin{array}{l}\text { Annealed copper } \\
\text { Annealed copper } \\
\text { Annealed copper } \\
\text { Annealed copper. }\end{array}$ & $\begin{array}{l}2.90 \\
2.96 \\
2.55 \\
2.55\end{array}$ & $\begin{array}{l}4,200 \\
4,300 \\
3,700 \\
3,700\end{array}$ & $\begin{array}{l}21.2 \\
21.4 \\
21.5 \\
21.4\end{array}$ & $\begin{array}{l}30,800 \\
31,000 \\
31,200 \\
31,100\end{array}$ & $\begin{array}{l}50.0 \\
49.0 \\
54.0 \\
53.0\end{array}$ \\
\hline
\end{tabular}

\section{Liquid-Against-Solid Collisions}

The small target plates of $1100-\mathrm{O}$ aluminum, 2024-O aluminum, and annealed electrolytic tough pitch copper were sent to Convair, Division of General Dynamics Corp., in San Diego, Calif., to be fired into drops of mercury $(0.1 \mathrm{~cm}$ and $0.2 \mathrm{~cm}$ in diam $)$ and drops of water $(0.2 \mathrm{~cm}$ in diam) at high speed. When the tests were made, the 1100-O aluminum targets were not fired because they were too thin.

The mercury drops used in the firings were individually weighed on an analytical balance, and the diameters of the drops were calculated. The actual diameters of the mercury drops and waterdrops varied in most cases by less than \pm 10 percent of the nominal size. The depths of the pits produced were measured at Convair using an optical micrometer; the depth measurements were reported to be good to $\pm 0.0013 \mathrm{~cm}( \pm 0.0005 \mathrm{in}$.$) .$

The theoretical curves for the collisions of liquid drops against solid targets were obtained using the equations [1]

$$
\delta^{\prime}=\frac{7.2 d z}{c\left(z+z^{\prime}\right)}\left[V-V_{i}\right]
$$

and

$$
V_{i}=\frac{19 E^{\prime}\left(z+z^{\prime}\right)}{\left(\rho c^{\prime} z^{\prime 3}\right)^{\frac{1}{2}}}
$$

in which $\delta^{\prime}$ is pit depth, $d$ is drop diameter, $c$ is the speed of sound as defined previously, $\rho$ is the density, $z$ is the acoustic impedance $(z=c \rho), E^{\prime}$ is the dynamic compressive yield strength of the target metal, $V_{i}$ is the smallest impingement velocity at which a permanent pit is made, and $V$ is the impingement velocity. Primed quantities refer to the material of the target 
TABLE 2. Constants of the materials of projectiles and targets

\begin{tabular}{|c|c|c|c|c|c|c|}
\hline \multirow{2}{*}{ Constant } & \multicolumn{3}{|c|}{ Projectile } & \multicolumn{3}{|c|}{ Target } \\
\hline & Water & Mercury & Steel & 1100-O Aluminum & 2024-O Aluminum & Copper electrolytic \\
\hline $\begin{array}{l}\text { Sound speed, } c . \mathrm{cm} / \mathrm{sec} \\
\text { Density, } \rho \ldots \mathrm{g} / \mathrm{cm}^{3} \\
\text { Acoustic impedance } \mathrm{f}, 2 \mathrm{~cm}{ }^{2} \mathrm{sec} \\
\text { Dynamic yield strength, } E^{\prime} \ldots \mathrm{dynes} / \mathrm{cm}^{2}\end{array}$ & $\begin{array}{l}\text { a } 1.497 \times 10^{5} \\
\text { c } 0.99707 \\
0.1493 \times 10^{6}\end{array}$ & $\begin{array}{l}\text { a } 1.451 \times 10^{5} \\
\text { e } 13.546 \\
\quad 1.966 \times 10^{6}\end{array}$ & $\begin{array}{l}\text { b } 5.786 \times 10^{5} \\
\text { d } 7.859 \\
\quad 4.547 \times 10^{6}\end{array}$ & $\begin{array}{l}\text { b } 6.318 \times 10^{5} \\
\text { e } 2.713 \\
\text { 1. } 714 \times 10^{6} \\
\text { g } 7.239 \times 10^{8}\end{array}$ & $\begin{array}{l}\text { b } 6.370 \times 10^{5} \\
\text { e } 2.768 \\
\text { 1. } 263 \times 10^{6} \\
\text { g } 2.350 \times 10^{9}\end{array}$ & $\begin{array}{l}\text { b } 4.691 \times 10^{5} \\
\text { e } 8.92 \\
\quad 4.184 \times 10^{6} \\
\text { h } 2.394 \times 10^{9}\end{array}$ \\
\hline
\end{tabular}

a Data from Bergmann [3].

b Measured in NBS Sound Section by C. E. Tschiegg.

- Data from Handbook of Chemistry and Physics.

d Data from Metals Handbook.

e Data from Aluminum Co. of America.

$\mathrm{f}$ A coustic impedance is the product of sound speed and density, $z=c \rho$.

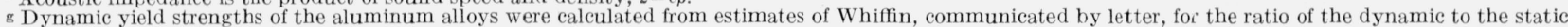
yield strength.

$\mathrm{h}$ Dynamic yield strength of copper is that given by Whiffin [2].

plate and unprimed quantities refer to the material of the liquid drop. All quantities are in $\operatorname{cgs}$ units. Values of these quantities for the materials used for projectiles and targets are listed in table 2 .

The development of eqs (1) and (2) has been given previously [1]. The conditions for valid use of these equations were discussed in section 1 .

\subsection{Collisions Between Metal Target Plates and Mercury Drops}

The experimental pit depths for collisions of $0.1-$ and $0.2-\mathrm{cm}$ mercury drops against target plates of annealed electrolytic tough pitch copper are listed in table 3 . They are plotted in figure 1 along with

TABLE 3. Experimental data ${ }^{a}$ for collisions of mercury drops of two sizes with annealed electrolytic tough pitch copper

\begin{tabular}{|c|c|c|c|c|c|}
\hline \multicolumn{3}{|c|}{ 0.1-cm drops } & \multicolumn{3}{|c|}{$0.2-\mathrm{cm}$ drops } \\
\hline $\begin{array}{l}\text { Collision } \\
\text { velocity }\end{array}$ & $\begin{array}{l}\text { Drop diam- } \\
\text { eter }\end{array}$ & Pit depth & $\begin{array}{l}\text { Collision } \\
\text { velocity }\end{array}$ & $\begin{array}{l}\text { Drop diam- } \\
\text { eter }\end{array}$ & Pit depth \\
\hline $\begin{array}{r}10^{4} \mathrm{~cm} / \mathrm{sec} \\
1.965 \\
1.965 \\
1.965 \\
1.955 \\
1.978\end{array}$ & $\begin{array}{l}\mathrm{cm} \\
0.0946 \\
.0913 \\
.1005 \\
.0956 \\
.1041\end{array}$ & $\begin{array}{l}c m \\
0.009_{4} \\
.010_{2} \\
.014_{0} \\
.016_{2} \\
.016_{3}\end{array}$ & $\begin{array}{r}10^{4} \mathrm{~cm} / \mathrm{sec} \\
\text { 1. } 773 \\
2.402 \\
2.542 \\
2.716 \\
2.779\end{array}$ & $\begin{array}{l}\mathrm{cm} \\
0.2027 \\
.2002 \\
.2064 \\
.1989 \\
.1953\end{array}$ & $\begin{array}{r}c m \\
0.029_{2} \\
.047_{8} \\
.066_{0} \\
.059_{7} \\
.058_{7}\end{array}$ \\
\hline $\begin{array}{l}2.432 \\
2.829 \\
3.246 \\
3.706 \\
\text { 3. } 761\end{array}$ & $\begin{array}{l}.0976 \\
.1037 \\
.1054 \\
.1102 \\
.0981\end{array}$ & $\begin{array}{l}.021_{6} \\
.029_{5} \\
.039_{1} \\
.044_{4} \\
.043_{7}\end{array}$ & $\begin{array}{l}2.841 \\
2.850 \\
2.865 \\
2.865 \\
2.890\end{array}$ & $\begin{array}{l}.2030 \\
.2113 \\
.2012 \\
.2012 \\
.2004\end{array}$ & $\begin{array}{l}.0640 \\
.0747 \\
.065_{5} \\
.0678 \\
.0650\end{array}$ \\
\hline $\begin{array}{l}\text { 3. } 944 \\
\text { 4. } 401 \\
\text { 4. } 724 \\
\text { 5. } 038 \\
\text { 5. } 371\end{array}$ & $\begin{array}{l}.1070 \\
.1045 \\
.0991 \\
.0951 \\
.0890\end{array}$ & $\begin{array}{l}.051_{3} \\
.058_{7} \\
.061_{5} \\
.059_{9} \\
.064_{5}\end{array}$ & $\begin{array}{l}2.984 \\
3.225 \\
3.310 \\
3.313 \\
3.438\end{array}$ & $\begin{array}{l}.1991 \\
.2032 \\
.1889 \\
.1951 \\
.2006\end{array}$ & $\begin{array}{l}.077_{0} \\
.082_{3} \\
.076_{37} \\
.076_{6} \\
.073_{7}\end{array}$ \\
\hline $\begin{array}{l}\text { 5. } 779 \\
6.126 \\
6.486 \\
6.772 \\
7.090\end{array}$ & $\begin{array}{l}.0956 \\
.1045 \\
.0951 \\
.1041 \\
.0991\end{array}$ & $\begin{array}{l}.074_{2} \\
.083_{6} \\
.084_{6} \\
.097_{3} \\
.093_{0}\end{array}$ & $\begin{array}{l}3.575 \\
3.663 \\
3.697 \\
3.986 \\
4.084\end{array}$ & $\begin{array}{l}.1972 \\
.2032 \\
.1997 \\
.2011 \\
.2006\end{array}$ & $\begin{array}{l}.0947 \\
.131_{8} \\
.083_{3} \\
.123_{2} \\
.107_{3}\end{array}$ \\
\hline $\begin{array}{l}7.388 \\
7.526 \\
8.074 \\
8.409 \\
8.708\end{array}$ & $\begin{array}{l}.1010 \\
.0991 \\
.0935 \\
.1065 \\
.1019\end{array}$ & $\begin{array}{l}.093_{2} \\
.097_{0} \\
.097_{0} \\
.1168 \\
.113_{8}\end{array}$ & $\begin{array}{l}\text { 4. } 096 \\
\text { 4. } 322 \\
4.401 \\
4.450 \\
4.862\end{array}$ & $\begin{array}{l}.2004 \\
.2048 \\
.2003 \\
.2025 \\
.1990\end{array}$ & $\begin{array}{l}.1107 \\
.1227 \\
.123_{2} \\
.123_{4} \\
.135_{4}\end{array}$ \\
\hline $\begin{array}{r}9.832 \\
10.50\end{array}$ & $\begin{array}{l}1028 \\
.1036\end{array}$ & $\begin{array}{l}.138_{9} \\
.130_{3}\end{array}$ & $\begin{array}{l}5.919 \\
6.069 \\
6.315 \\
6.410 \\
6.461\end{array}$ & $\begin{array}{l}.2099 \\
.2046 \\
.2018 \\
.1995 \\
.1990\end{array}$ & $\begin{array}{l}.191_{4} \\
.179_{2} \\
.177_{5} \\
.169_{9} \\
.199_{9}\end{array}$ \\
\hline
\end{tabular}

a See footnote 2 . theoretical curves calculated using eqs (1) and (2) and the data in table 2. The theoretical curves are in relatively good agreement with the experimental points. The effect of the change in drop size is properly accounted for by the theoretical equations. Curve A, calculated for the $0.1-\mathrm{cm}$ drop size, is in better agreement with the observed depths produced by collision with $0.1-\mathrm{cm}$ drops than curve B, calculated for the $0.2-\mathrm{cm}$ drop size, is with the observed depths produced by collision with $0.2-\mathrm{cm}$ drops. The assumption of spherical drops used in calculating drop diameters from the weight of the mercury drops can be expected to be more accurate for the smaller drop size. In this connection, it is noteworthy that there is more scatter in the experimental data for the 0.2 -cm drop size.

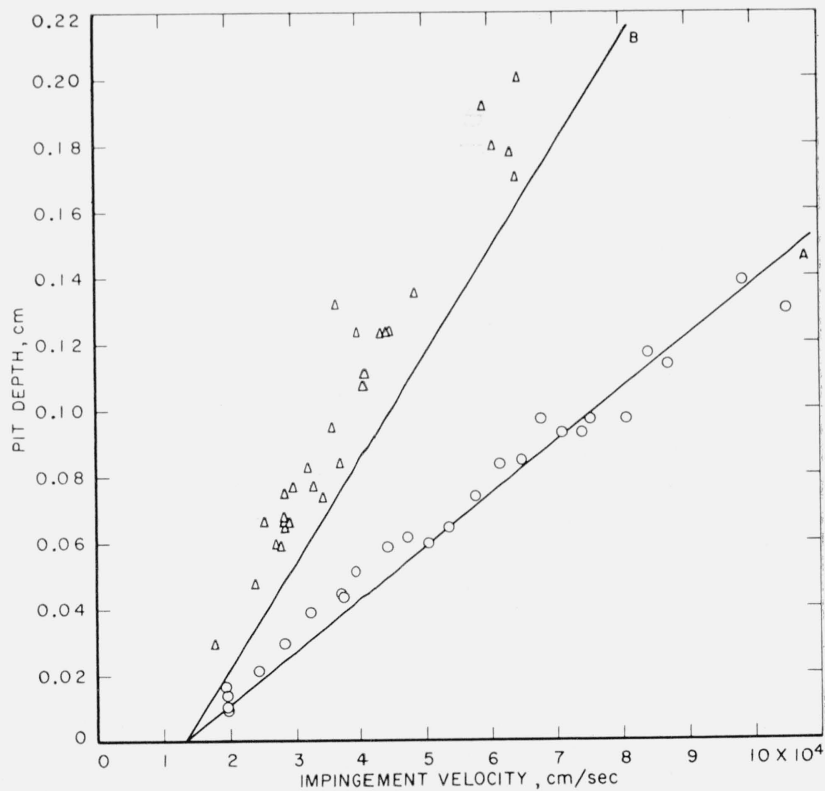

Figure 1. Collisions of mercury drops of two sizes against annealed electrolytic tough pitch copper.

Curve A, calculated using eqs (1) and (2) for 0.1-cm drops; $\odot$, observed depth produced by collision with $0.1-\mathrm{cm}$ drops Curve B, calculated using eqs (1) and (2) for 0.2-em drops; $\triangle$. observed depth produced by collision with 02 -cm drops 
On the other hand, if the calculated intercept velocity, $V_{i}$, had been a little smaller, the fit would have been better. The dynamic compressive yield strength reported by Whiffin [2] for electrolytic copper was used for $E^{\prime}$ in computing $V_{i}$ for the theoretical curves (see table 2). It is not known if the electrolytic copper for which Whiffin [2] obtained the dynamic compressive yield strength was equivalent to the electrolytic tough pitch copper that was used for the target plates. Whiffin [2] did not report the static yield strength of the electrolytic copper that he used; he described it as being normally very soft and giving no definite indication of yield strength in static compression tests. No formula exists for copper by means of which the dynamic compressive yield strength can be calculated from the static yield strength; however, the latter provides a means of identification that can be reproduced by others.

The experimental pit depths for collisions of 0.1 and $0.2-\mathrm{cm}$ mercury drops with target plates of $2024-\mathrm{O}$ aluminum are listed in table 4 . They are plotted in figure 2 with the theoretical curves calculated using eqs (1) and (2) and the data in table 2. The theoretical curves are in reasonably good agreement with the experimental points. As was found to be true in figure 1 , the effect of the change in drop size is properly accounted for by the theoretical equations. As in the case of the copper targets,

TABLE 4. Experimental data for collisions of mercury drops of two sizes with 2024-O aluminum

\begin{tabular}{|c|c|c|c|c|c|}
\hline \multicolumn{3}{|c|}{$0.1-\mathrm{cm}$ drops } & \multicolumn{3}{|c|}{$0.2-\mathrm{cm}$ drops } \\
\hline $\begin{array}{l}\text { Collision } \\
\text { velocity }\end{array}$ & $\begin{array}{l}\text { Drop } \\
\text { diameter }\end{array}$ & Pit depth & $\begin{array}{l}\text { Collision } \\
\text { velocity }\end{array}$ & $\begin{array}{l}\text { Drop } \\
\text { diameter }\end{array}$ & Pit depth \\
\hline $\begin{array}{r}10^{4} \mathrm{~cm} / \mathrm{sec} \\
1.966 \\
\text { 2. } 454 \\
2.816 \\
2.890 \\
3.413\end{array}$ & $\begin{array}{l}c m \\
0.1032 \\
.0956 \\
.0940 \\
.1032 \\
.0976\end{array}$ & $\begin{array}{l}c m \\
0.080_{0} \\
.020_{1} \\
.023_{4} \\
.0256 \\
.0353\end{array}$ & $\begin{array}{r}10^{4} \mathrm{~cm} / \mathrm{sec} \\
1.759 \\
2.316 \\
2.554 \\
2.682 \\
2.789\end{array}$ & $\begin{array}{l}c m \\
0.19514 \\
.19175 \\
.1998 \\
.0122 \\
.1969\end{array}$ & $\begin{array}{r}c m \\
0.012_{4} \\
.0272 \\
.038_{4} \\
.048_{4} \\
.049_{0}\end{array}$ \\
\hline $\begin{array}{l}\text { 3. } 627 \\
\text { 3. } 797 \\
\text { 3. } 822 \\
\text { 4. } 322 \\
\text { 4. } 669\end{array}$ & $\begin{array}{l}.0996 \\
.1037 \\
.0996 \\
.1037 \\
.1009\end{array}$ & $\begin{array}{l}.044_{7} \\
.049_{0} \\
.046_{1} \\
.006_{5} \\
.067_{6}\end{array}$ & $\begin{array}{l}3.048 \\
3.200 \\
3.377 \\
3.596 \\
4.008\end{array}$ & $\begin{array}{l}.1984 \\
.2017 \\
.19672 \\
.20330 \\
.2047\end{array}$ & $\begin{array}{l}.055_{9} \\
.071_{1} \\
.0856 \\
.094_{4} \\
.264_{2}\end{array}$ \\
\hline $\begin{array}{l}4.745 \\
\text { 4. } 995 \\
5.145 \\
5.517 \\
5.752\end{array}$ & $\begin{array}{l}.0946 \\
.1041 \\
.1000 \\
.1058 \\
.1014\end{array}$ & $\begin{array}{l}.059_{4} \\
.076_{7} \\
.077_{2} \\
.093_{7} \\
.095_{3}\end{array}$ & $\begin{array}{l}\text { 4. } 084 \\
\text { 4. } 517 \\
\text { 5. } 489 \\
5.727 \\
6.834\end{array}$ & $\begin{array}{l}.2031 \\
.2010 \\
.20572 \\
.2000 \\
.1982\end{array}$ & $\begin{array}{l}.109_{5} \\
.259_{1} \\
.241_{6} \\
.206_{5} \\
.264_{7}\end{array}$ \\
\hline $\begin{array}{l}6.004 \\
66.066 \\
6.251 \\
6.736 \\
7.047\end{array}$ & $\begin{array}{l}.0971 \\
.0961 \\
.1032 \\
.1028 \\
.0971\end{array}$ & $\begin{array}{l}.099_{1} \\
.096_{8} \\
.112_{5} \\
.130_{8} \\
.124_{1}\end{array}$ & & & \\
\hline $\begin{array}{l}\text { 7. } 047 \\
7.525 \\
8.019 \\
8.071 \\
8.074\end{array}$ & $\begin{array}{l}.0971 \\
.1032 \\
.1028 \\
.1037 \\
.1014\end{array}$ & $\begin{array}{l}.149_{9} \\
.013_{3} \\
.146_{6} \\
.159_{8} \\
.148_{8}\end{array}$ & & & \\
\hline $\begin{array}{l}\text { 8. } 525 \\
\text { 8. } 772 \\
9.195 \\
9.229 \\
9.623\end{array}$ & $\begin{array}{l}.1023 \\
.1045 \\
.0946 \\
.0966 \\
.1019\end{array}$ & $\begin{array}{l}.166_{5} \\
.176_{3} \\
.162_{8} \\
.163_{6} \\
.182_{9}\end{array}$ & & & \\
\hline 10.06 & .0956 & $.162_{6}$ & & & \\
\hline
\end{tabular}

a See footnote 2 .

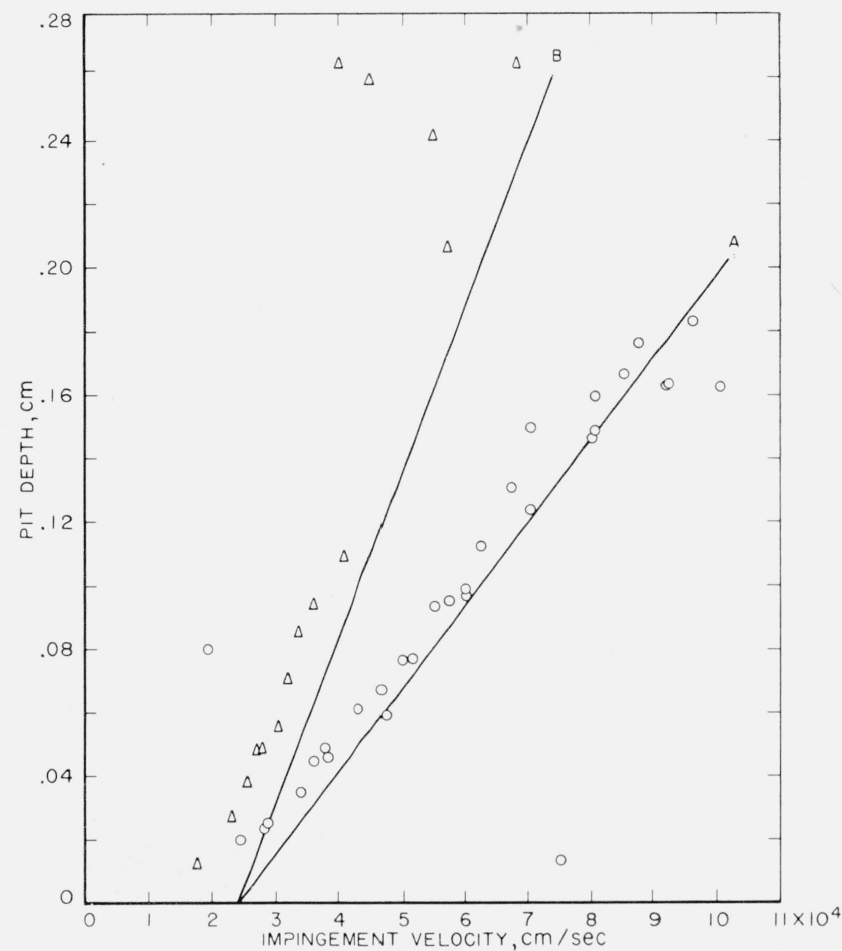

Figure 2. Collisions of mercury drops of two sizes against 2024-O aluminum

Curve A, calculated using eqs (1) and (2) for 0.1-cm drops; $\odot$, observed depth produced by collision with $0.1-\mathrm{cm}$ drops; $\odot$, observed depth produced by collision with $0.1-\mathrm{cm}$ drops;
Curve B, calculated using eqs (1) and (2) for $0.2-\mathrm{cm}$ drops; $\triangle$, observed depth produced by collision with $0.2-\mathrm{cm}$ drops.

curve A, calculated for the 0.1-cm drop size, is in better agreement with the observed depths produced by collision with $0.1-\mathrm{cm}$ drops than curve B, calculated for the $0.2-\mathrm{cm}$ drop size, is with the observed depths produced by collision with $0.2-\mathrm{cm}$ drops. There is quite a bit of scatter in the experimental points for both drop sizes.

As in the case of the pit-depth-versus-velocity data for copper, there would be better agreement between the theoretical curves and the empirical data if the calculated intercept velocity, $V_{i}$, were smaller. In the case of the 2024-O aluminum, the dynamic yield strength used for $E^{\prime}$ in computing $V_{i}$ was calculated from the measured static yield strength (see table 2) and should be fairly reliable.

The numerical constants used in eqs (1) and(2) were originally chosen [1] using pit-depth-versusvelocity data (see footnote 2) for metals whose static yield strength and whose sound speed in infinite medium were not measured experimentally. It may be found necessary to change the constants in the equations to some extent when more pit-depthversus-velocity data become available using targets of metals for which these quantities have been measured.

Although eq (2) appears to be the most acceptable expression for the intercept velocity on the basis of the available experimental data for collisions of 
liquid drops against solids [1], it is possible that, when more data are obtained and the problem is studied further, it may be found necessary to modify it.

\subsection{Collisions Between Metal Target Plates and Waterdrops}

The experimental pit depths for collisions of $0.2-\mathrm{cm}$ waterdrops against target plates of annealed electrolytic tough pitch copper are listed in table 5 . They are plotted in figure 3 with the theoretical curve calculated using eq (1) and (2) and the data in table 2 . The theoretical curve is in acceptable agreement both as to slope and intercept with the experimental data. There is, unfortunately, a large amount of scatter in the experimental data which reduces their effectiveness as a check of the theoretical equations.

TABLE 5. Experimental data for collisions of 0.2-cm waterdrops with annealed electrolytic tough pitch copper

\begin{tabular}{r|r}
\hline \hline $\begin{array}{c}\text { Collision } \\
\text { velocity }\end{array}$ & Pit depth \\
\hline & \\
\hline $10^{4} \mathrm{~cm} / \mathrm{sec}$ & $\mathrm{cm}$ \\
4.593 & $0.003_{0}$ \\
4.983 & $.005_{1}$ \\
5.297 & $.009_{4}$ \\
5.486 & $.093_{6}$ \\
6.111 & $.010_{4}$ \\
6.584 & $.009_{9}$ \\
6.660 & $.006_{1}$ \\
7.041 & $.013_{0}$ \\
7.041 & $.019_{3}$ \\
8.839 & $.017_{0}$ \\
\hline
\end{tabular}

a See footnote 2 .

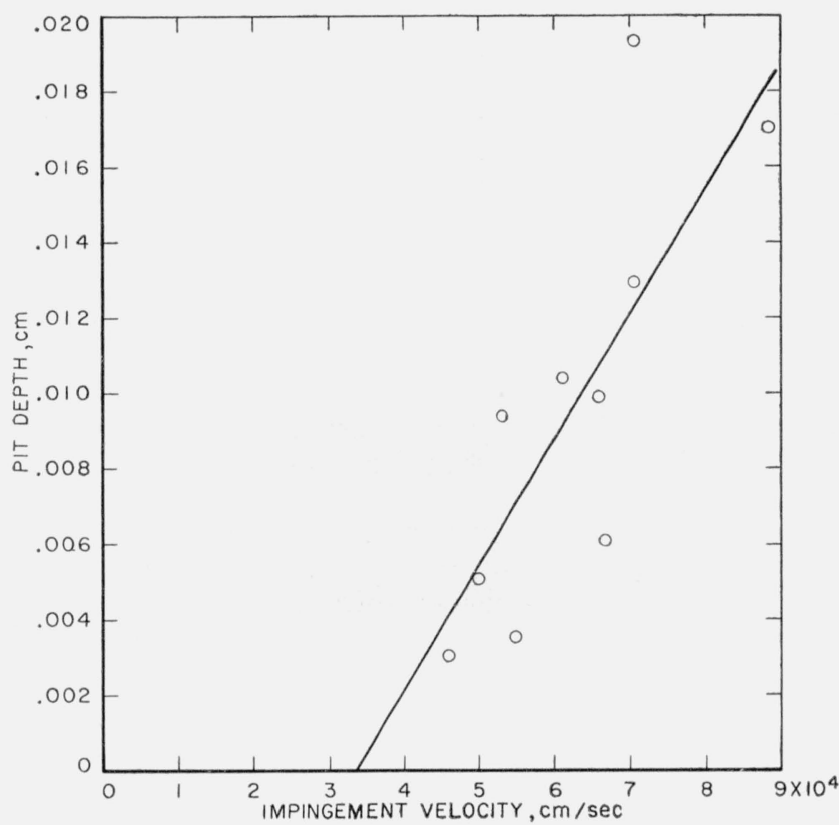

F1GLRE 3. Collisions of 0.2-cm waterdrops against annealed electrolytic tough pitch copper

_. calculated using eqs (1) and (2) for 0.2-cm drops; $\odot$, observed depth produced by collision with $0.2-\mathrm{cm}$ drops.
The experimental pit depths for collisions of $0.2-\mathrm{cm}$ waterdrops against target plates of 2024-O aluminum are listed in table 6 . They are plotted in figure 4 with the theoretical curve calculated using eqs (1) and (2) and the data of table 2. The theoretical curve is a good fit for the experimental data both as to slope and intercept. This is more significant than the extent of agreement found between the theoretical curve and the experimental data in figure 3 because there is considerably less scatter in these data than in those obtained with the copper targets.

The agreement found between the theoretical curves and the experimental data in figures 3 and 4 is an indication that eqs (1) and (2) may be reliable

TABLE 6. Experimental data for collisions of 0.2-cm waterdrops with 2024-O aluminum

\begin{tabular}{r|r}
\hline $\begin{array}{c}\text { Collision } \\
\text { velocity }\end{array}$ & \multicolumn{1}{|c}{ Pit depth } \\
\hline $10^{4} \mathrm{~cm} / \mathrm{sec}$ & \multicolumn{2}{|c}{$\mathrm{cm}$} \\
4.581 & $0.002_{3}$ \\
4.581 & $.002_{5}$ \\
4.852 & $.005_{3}$ \\
5.456 & $.004_{6}$ \\
6.370 & $.010_{7}$ \\
6.584 & $.011_{7}$ \\
7.224 & $.014_{7}$ \\
7.498 & .0206 \\
& \\
\hline
\end{tabular}

a See footnote 2 .

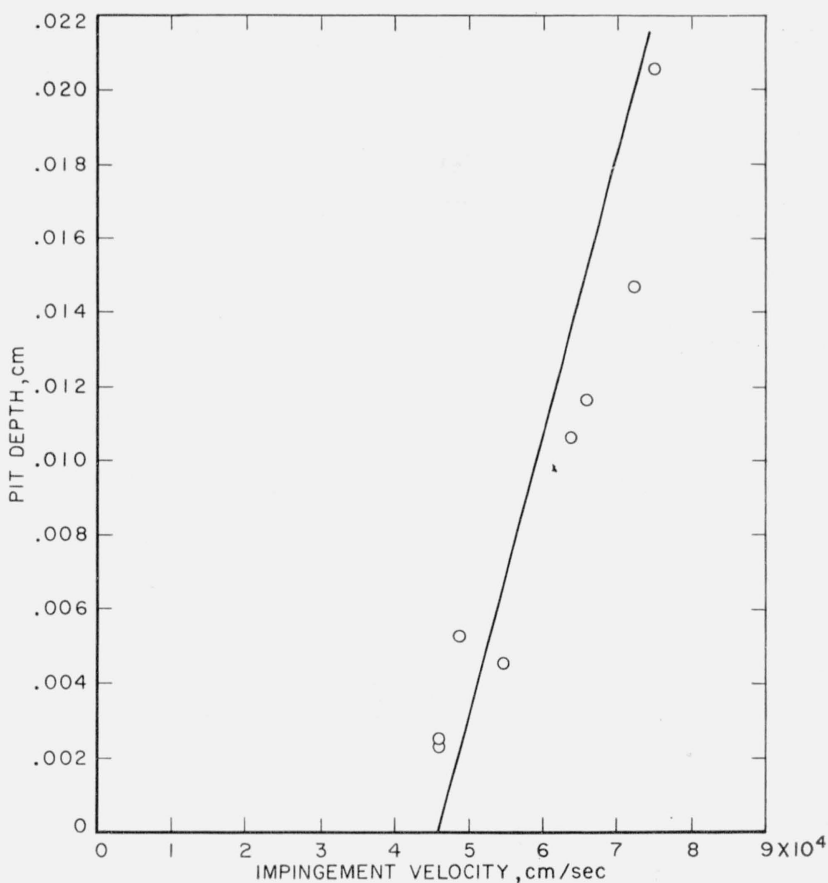

Figure 4. Collisions of 0.2-cm waterdrops against 2024-O aluminum.

calculated using eqs (1) and (2) for 0.2-cm drops; $\odot$, observed depth produced by collision with 0.2 -cm drops. 
in their present form for calculating the depths of pits formed in the soft and medium hard metals as a result of collision with liquid drops. Although the speed of sound in mercury is nearly identical with the speed of sound in water, the density, and, therefore, the acoustic impedance, of mercury is very much higher than that of water. Further test of the equations should be made, however, using drops of a liquid that has a sound speed different from that of mercury or water.

\section{Solid-Aggainst-Solid Collisions}

Because the pit-depth-versus-velocity equation developed [1] for collisions of target plates of the soft and medium hard metals with liquid drops ignored such characteristic fluid-flow parameters as the Weber number and the Reynolds number, it should apply equally well to pits produced by collision of solid spheres with target plates of the same types of metals. The equation may, in fact, be substantiated further with data of this kind. To explore this possibility, 2.5-cm- (1-in.-) thick plates of $1100-\mathrm{O}$ aluminum, 2024-O aluminum, and annealed electrolytic tough pitch copper were used as targets for steel sphere impingement. The test firings were made at the U.S. Naval Research Laboratory in Washington, D.C., under the direction of Mr. Wilfred J. Ferguson and Mr. Harry O. Ewing. Most of the shots were made using a target mounting in which the plate was given edge support only. In this form of mounting the rear face of the target plate was a free surface. These data are presented and discussed in sections $4.1,4.2$, and 4.3. One set of data was obtained for collisions of steel spheres against 2024-O aluminum target plates backed with a 12.7-by-15.2-cm (5-by-6in.) steel supporting block $7.6-\mathrm{cm}$ (3-in.) thick. In this form of mounting the rear face of the target plate was not a free surface. These data are presented and discussed in section 4.4.

The velocity measurements were made using a Potter chronograph. The base length was $30.5 \mathrm{~cm}$ (12 in.). The chronograph was started and stopped by breaking conducting grids. The distance from the midpoint of the base length to the target face was $58.4 \mathrm{~cm}$ (23 in.); the velocity measurements were not corrected for deceleration of the steel spheres during transit over this distance.

The steel spheres were SKF Grade 1 and had an approximate hardness of 60 on the Rockwell $\mathrm{C}$ scale. These spheres have a high order of accuracy in dimensions because they are made for ball bearings. Three sphere sizes were used for the firings: $0.5556-\mathrm{cm}$ (7/32-in.), $0.7938-\mathrm{cm}$ (5/16-in.), and $1.270-\mathrm{cm}$ (1/2-in.) diameter.

The depths of the pits produced by impingement of the steel spheres against target plates of the three metals were measured using an Ames dial gauge graduated in mils. Each depth measurement is the difference between the dial reading at the pit bottom and an average of four dial readings taken on the surface of the target plate around the mouth of the crater.

\subsection{Collisions of Steel Spheres With Target Plates of 1100-O Aluminum}

The velocities at which the shots were made and the depths of the pits produced in the 1100-O aluminum plates are given in table 7 for the three sizes of steel spheres used.

The pit-depth-versus-velocity curve for collisions of steel spheres with $1100-\mathrm{O}$ aluminum was first calculated according to the equations that were developed for collisions between metal target plates and liquid drops. Although the experimental pitdepth-versus-velocity data were found to lie along straight lines, the slope of the lines was found to be much steeper than that of the lines given by the pitdepth-versus-velocity equation for collision of liquid drops against target plates of the soft and medium hard metals. This is to be expected because in the case of the very hard steel-sphere projectiles most of the collision energy is used in forming the pits, whereas in the case of projectiles that flow during: and as a result of the collision, part of the collision energy is used in the flow of the projectile.

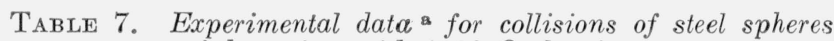
of three sizes with 1100-O aluminum

\begin{tabular}{|c|c|c|c|c|c|}
\hline \multicolumn{2}{|c|}{$\begin{array}{l}\text { Sphere diameter } 0.5556 \\
\mathrm{~cm}(7 / 32 \text { in.) }\end{array}$} & \multicolumn{2}{|c|}{$\begin{array}{l}\text { Sphere diameter } 0.7938 \\
\mathrm{~cm}(5 / 16 \text { in.) }\end{array}$} & \multicolumn{2}{|c|}{$\begin{array}{l}\text { Sphere diameter } 1.270 \\
\mathrm{~cm}(1 / 2 \text { in.) }\end{array}$} \\
\hline Velocity & Pit depth & Velocity & Pit depth & Velocity & Pit depth \\
\hline $\begin{array}{c}10^{4} \mathrm{~cm} / \mathrm{sec} \\
0.9784 \\
1.018 \\
1.049 \\
1.411 \\
1.457\end{array}$ & $\begin{array}{r}c m \\
0.10_{0} \\
.10_{4} \\
.10_{7} \\
.14_{8} \\
.15_{1}\end{array}$ & $\begin{array}{c}10^{4} \mathrm{~cm} / \mathrm{sec} \\
0.7163 \\
.9723 \\
1.265 \\
1.414 \\
1.490\end{array}$ & $\begin{array}{c}c m \\
0.11_{0} \\
.14_{6} \\
.19_{2} \\
.21_{2} \\
.22_{4}\end{array}$ & $\begin{array}{r}10^{4} \mathrm{~cm} / \mathrm{sec} \\
0.887 \\
1.055 \\
1.295 \\
1.558 \\
1.609\end{array}$ & $\begin{array}{r}\text { cm } \\
0.22_{4} \\
.27_{2} \\
.32_{9} \\
.37_{5} \\
.39_{2}\end{array}$ \\
\hline $\begin{array}{l}1.704 \\
1.871 \\
2.140 \\
2.146 \\
2.576\end{array}$ & $\begin{array}{l}.18_{0} \\
.19_{9} \\
229 \\
23_{3} \\
.29_{1}\end{array}$ & $\begin{array}{l}1.506 \\
1.530 \\
1.646 \\
1.661 \\
1.783\end{array}$ & $\begin{array}{l}.23_{4} \\
.23_{4} \\
.25_{3} \\
.25_{6} \\
.27_{6}\end{array}$ & $\begin{array}{l}1.759 \\
1.807 \\
2.009 \\
2.082 \\
2.121\end{array}$ & $\begin{array}{l}.448 \\
.46_{6} \\
.52_{6} \\
.55_{6} \\
.60_{8}\end{array}$ \\
\hline $\begin{array}{l}2.865 \\
3.103\end{array}$ & $\begin{array}{l}.34_{4} \\
.37_{3}\end{array}$ & $\begin{array}{l}1.789 \\
1.862 \\
1.993 \\
2.137 \\
2.423\end{array}$ & $\begin{array}{l}.27_{5} \\
.297 \\
.31_{7} \\
.34_{1} \\
.378\end{array}$ & $\begin{array}{l}2.128 \\
2.414\end{array}$ & $\begin{array}{l}.55_{4} \\
.65_{6}\end{array}$ \\
\hline
\end{tabular}

a These data were obtained at the U.S. Naval Research Laboratory, Washington, D.C.

To fit the experimental data, it was found by trial that it was necessary to increase the numerical constant in the expression for pit depth to 17.5 and to reduce the numerical constant in the expression for the intercept velocity to 1 . With these changes, the pit-depth-versus-velocity equation for collisions of projectiles that neither flow nor undergo appreciable permanent yield with targets of the soft and medium hard metals is

$$
\delta^{\prime}=\left[17.5 d z / c\left(z+z^{\prime}\right)\right] \cdot\left[V-V_{i}\right]
$$

where

$$
V_{i}=E^{\prime}\left(z+z^{\prime}\right) /\left(\rho c^{\prime} z^{\prime 3}\right) \frac{1}{2}
$$

The theoretical pit-depth-versus-velocity curves, calculated using eqs (3) and (4) and the data in table 2 , for collisions of steel spheres of three sizes against 
1100-O aluminum target plates are shown with the experimentally determined points in figure 5. The experimental points lie along the theoretical curves. In particular, it can be seen that the effect of a change in sphere size is properly accounted for by the equations.

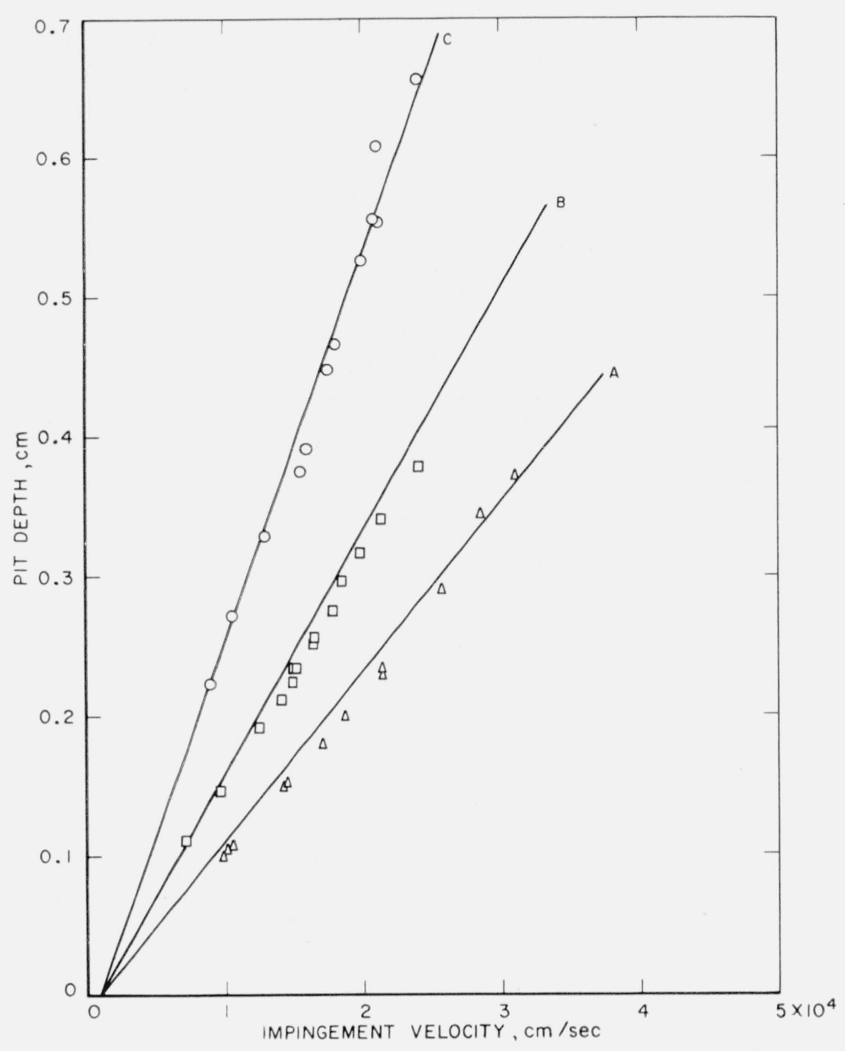

Figure 5. Collisions of steel spheres of three sizes against 1100-O aluminum.

Curve A, calculated using eqs (3) and (4) for 0.5556-cm (7/32-in.) spheres; $A$, observed depth produced by collision with $0.5556-\mathrm{cm}(7 / 32-\mathrm{in}$.) spheres; Curve B, calculated using eqs (3) and (4) for 0.7938-cm (5/16-in.) spheres; , observed depth produced by collision with $0.7938-\mathrm{cm}(5 / 16$-in.) spheres; Curve C, calculated using eqs (3) and (4) for $1.270-\mathrm{cm}$ (1/2-in.) spheres; $\odot$, observed depth produced by collision with $1.270-\mathrm{cm}(1 / 2-\mathrm{in}$.) spheres.

\subsection{Collisions of Steel Spheres With Target Plates of Annealed Electrolytic Tough Pitch Copper}

The velocity at which the shots were made and the depth of the pits produced with three sizes of steel spheres against 2.5-cm-(1-in.-) thick plates of annealed electrolytic tough pitch copper are given in table 8 . Theoretical pit-depth-versus-velocity curves, calculated using eq (3) and (4) and the data in table 2, are shown with the experimentally determined points in figure 6 . There is quite a bit of scatter in the experimental data for the $1.270-\mathrm{cm}-(1 / 2-10 .-)$ diam steel spheres. Nevertheless, there is, in general, good agreement between the theoretical curves and the observed points. The effect of a change in sphere size is properly accounted for by the equations.
TaBLe 8. Experimental data a for collisions of steel spheres of three sizes with annealed electrolytic tough pitch copper

\begin{tabular}{|c|c|c|c|c|c|}
\hline \multicolumn{2}{|c|}{$\begin{array}{l}\text { Sphere diameter } \\
0.5556 \mathrm{~cm}(7 / 32 \mathrm{in} .)\end{array}$} & \multicolumn{2}{|c|}{$\begin{array}{c}\text { Sphere diameter } \\
0.7938 \mathrm{~cm}(5 / 16 \mathrm{in} .)\end{array}$} & \multicolumn{2}{|c|}{$\begin{array}{l}\text { Sphere diameter } \\
1.270 \mathrm{~cm} \text { (1/2 in.) }\end{array}$} \\
\hline Velocity & Pit depth & Velocity & Pit depth & Velocity & Pit depth \\
\hline $\begin{array}{r}10^{4} \mathrm{~cm} / \mathrm{sec} \\
1.100 \\
1.372 \\
1.500 \\
1.878 \\
1.981\end{array}$ & $\begin{array}{c}c m \\
0.08_{7} \\
.10_{3} \\
.154 \\
.138 \\
.14_{5}\end{array}$ & $\begin{array}{c}10^{4} \mathrm{~cm} / \mathrm{sec} \\
0.7803 \\
.9388 \\
1.119 \\
1.283 \\
1.588\end{array}$ & $\begin{array}{c}c m \\
0.09_{0} \\
.10_{9} \\
.12_{4} \\
.14_{5} \\
.17_{3}\end{array}$ & $\begin{array}{r}10^{4} \mathrm{~cm} / \mathrm{sec} \\
0.4084 \\
.4389 \\
.9601 \\
1.333 \\
1.411\end{array}$ & $\begin{array}{r}\mathrm{cm} \\
0.08_{3} \\
.092 \\
.18_{2} \\
.240 \\
.249\end{array}$ \\
\hline $\begin{array}{l}2.121 \\
2.124 \\
2.158 \\
2.225 \\
2.234\end{array}$ & $\begin{array}{l}.156 \\
.159 \\
.16_{7} \\
.166 \\
.166\end{array}$ & $\begin{array}{l}\text { 1. } 740 \\
\text { 2. } 280 \\
\text { 2. } 377 \\
\text { 2. } 457\end{array}$ & $\begin{array}{l}.188 \\
.249 \\
.26_{2} \\
.27_{4}\end{array}$ & $\begin{array}{l}\text { 1. } 426 \\
1.451 \\
1.868 \\
\text { 1. } 966 \\
\text { 2. } 036\end{array}$ & $\begin{array}{l}.250 \\
.309 \\
.301 \\
.354 \\
.369\end{array}$ \\
\hline $\begin{array}{l}\text { 2. } 256 \\
\text { 2. } 271 \\
\text { 2. } 316 \\
2.646 \\
2.685\end{array}$ & $\begin{array}{l}.170 \\
.17_{2} \\
.17_{6} \\
.202 \\
.206\end{array}$ & & & $\begin{array}{l}\text { 2. } 060 \\
2.134 \\
2.204 \\
2.216 \\
2.694\end{array}$ & $\begin{array}{l}.377 \\
.425 \\
.395 \\
.400 \\
.573\end{array}$ \\
\hline $\begin{array}{l}\text { 2. } 960 \\
\text { 3. } 560\end{array}$ & $\begin{array}{l}.233 \\
.280\end{array}$ & & & $\begin{array}{l}\text { 2. } 704 \\
\text { 3. } 066 \\
\text { 3. } 109 \\
\text { 3. } 225 \\
\text { 3. } 432\end{array}$ & $\begin{array}{l}.38_{8} \\
.580 \\
.49_{5} \\
.62_{2} \\
.638\end{array}$ \\
\hline
\end{tabular}

a These data were obtained at the U.S. Naval Research Laboratory, Wash ton, D.C.

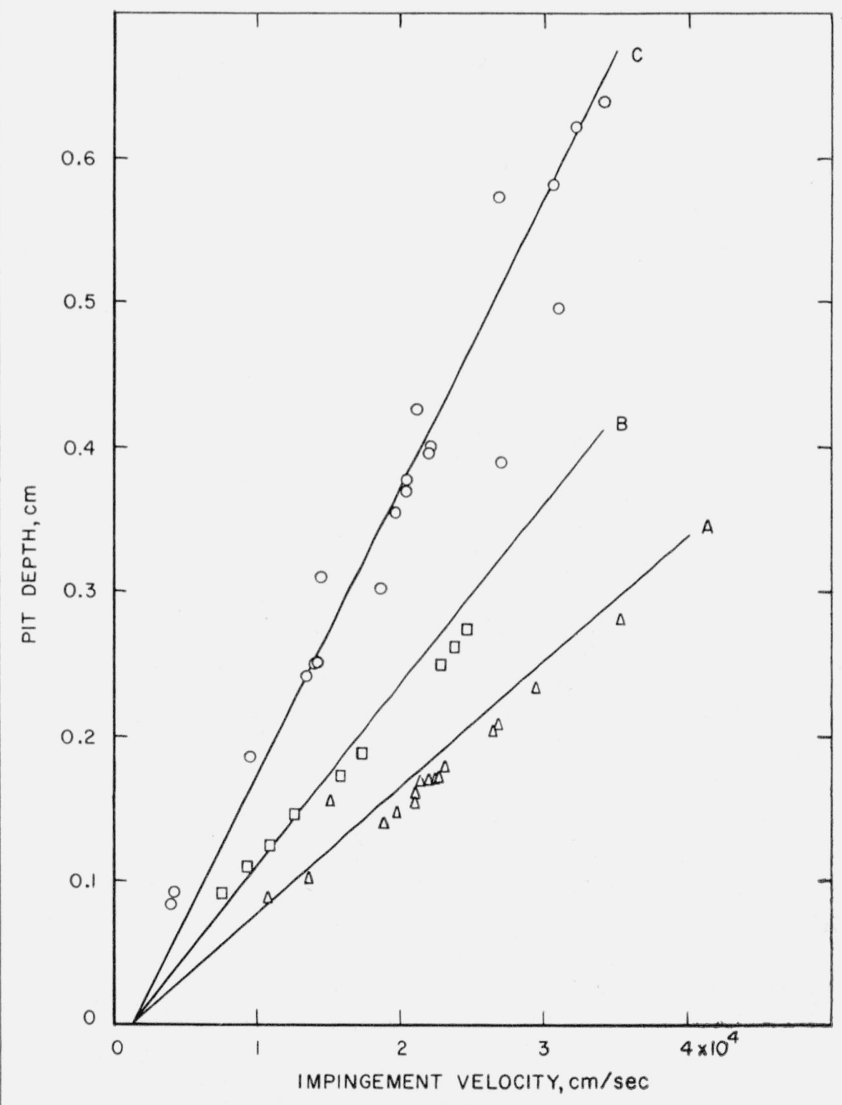

Figure 6. Collisions of steel spheres of three sizes against annealed electrolytic tough pitch copper.

Curve A, calculated using eqs (3) and (4) for 0.5556-cm (7/32-in.) spheres; $\Delta$, observed depth produced by collision with $0.5556-\mathrm{cm}(7 / 32-i n$.) spheres Curve B, calculated using eqs (3) and (4) for 0.7938-cm (5/16-in.) spheres; $\checkmark$, observed depth produced by collision with $0.7938-\mathrm{cm}(5 / 16$-in.) spheres Curve C, calculated using eqs (3) and (4) for 1.270-cm (1/2-in.) spheres; $\odot$, observed depth produced by collision with $1.270-\mathrm{cm}(1 / 2-\mathrm{in}$.) spheres 


\subsection{Collisions of Steel Spheres With Target Plates of 2024-O Aluminum}

The velocity at which shots with three sphere sizes were made against plates of 2024-O aluminum and the depths of the pits that were produced by the shots are given in table 9. Theoretical pit-depthversus-velocity curves calculated using eq (3) and (4) and the data in table 2 are shown with the experimental data in figure 7 . For each sphere size used, the experimental points lie below the theoretical curve.

TABLE 9. Experimental data a for collisions of steel spheres of three sizes with 2024-O aluminum

\begin{tabular}{|c|c|c|c|c|c|}
\hline \multicolumn{2}{|c|}{$\begin{array}{l}\text { Sphere diameter } 0.5556 \\
\mathrm{~cm}(7 / 32 \text { in. })\end{array}$} & \multicolumn{2}{|c|}{$\begin{array}{l}\text { Sphere diameter } 0.7938 \\
\mathrm{~cm}(5 / 16 \text { in.) }\end{array}$} & \multicolumn{2}{|c|}{$\begin{array}{c}\text { Sphere diameter } 1.270 \\
\mathrm{~cm}(1 / 2 \mathrm{in.})\end{array}$} \\
\hline Velocity & Pit depth & Velocity & Pit depth & Velocity & Pit depth \\
\hline $\begin{array}{r}10^{4} \mathrm{~cm} / \mathrm{sec} \\
1.113 \\
1.451 \\
1.542 \\
1.981 \\
2.173\end{array}$ & $\begin{array}{c}c m \\
0.079 \\
.103 \\
.109 \\
.135 \\
.15_{6}\end{array}$ & $\begin{array}{c}10^{4} \mathrm{~cm} / \mathrm{sec} \\
0.7894 \\
1.067 \\
1.305 \\
1.698 \\
1.771\end{array}$ & $\begin{array}{c}\mathrm{cm} \\
0.08_{0} \\
.10_{7} \\
.149 \\
.173 \\
.18_{0}\end{array}$ & $\begin{array}{c}10^{4} \mathrm{~cm} / \mathrm{sec} \\
0.5578 \\
.5822 \\
1.207 \\
1.326 \\
1.460\end{array}$ & $\begin{array}{r}\mathrm{cm} \\
0.19_{7} \\
.17_{2} \\
.19_{7} \\
.26 \mathrm{~s} \\
.248\end{array}$ \\
\hline $\begin{array}{l}\text { 2. } 274 \\
\text { 2. } 368 \\
\text { 2. } 448 \\
\text { 2. } 701\end{array}$ & $\begin{array}{l}.18_{8} \\
.169 \\
.178 \\
.197\end{array}$ & $\begin{array}{l}\text { 1. } 832 \\
\text { 2. } 856\end{array}$ & $\begin{array}{l}.185 \\
.349\end{array}$ & $\begin{array}{l}2.039 \\
2.722 \\
2.780 \\
2.786 \\
3.301 \\
\\
3.484 \\
3.548 \\
3.658\end{array}$ & $\begin{array}{l}.34_{5} \\
.48_{2} \\
.493 \\
.49_{1} \\
.622 \\
.36_{0} \\
.62 \\
.60_{6}\end{array}$ \\
\hline
\end{tabular}

a These data were obtained at the U.S. Naval Research Laboratory, Washington, D.C.

Four possible reasons for this discrepancy were explored. (1) In steel-sphere collisions with materials as strong as 2024-O aluminum the steel sphere may be permanently deformed and in this way part of the collision energy may be diverted from pit formation, whereas in the case of the very soft metals all of the collision energy may go into pit formation. (2) In view of the fact that heat-treated 2024 aluminum is subject to spalling, energy may be diverted from pit formation into crack formation, although this is unlikely in the case of the annealed metal. (3) Sound is attenuated to different degrees in the target metals used. (4) The target metals that were used work-harden by different amounts.

To check the first possibility, two $1.270-\mathrm{cm}-(1 / 2-$ in.-) diam steel spheres that were fired against target plates of annealed copper and 2024-O aluminum, respectively, were recovered. The sphere that struck the copper target plate had a collision velocity of $3.432 \times 10^{4} \mathrm{~cm} / \mathrm{sec}(1,126 \mathrm{ft} / \mathrm{sec})$ and the sphere that struck the 2024-O aluminum target plate had a collision velocity of $3.650 \times 10^{4} \mathrm{~cm} / \mathrm{sec}(1,200 \mathrm{ft} / \mathrm{sec})$. These spheres were examined with a microinterferometer in the NBS Engineering Metrology Section. It was found that the diameter measured through the impact area of the sphere shot into copper was $0.0025 \mathrm{~cm}(0.0010 \mathrm{in}$.) smaller than diameters measured outside of the impact area and that the diam-

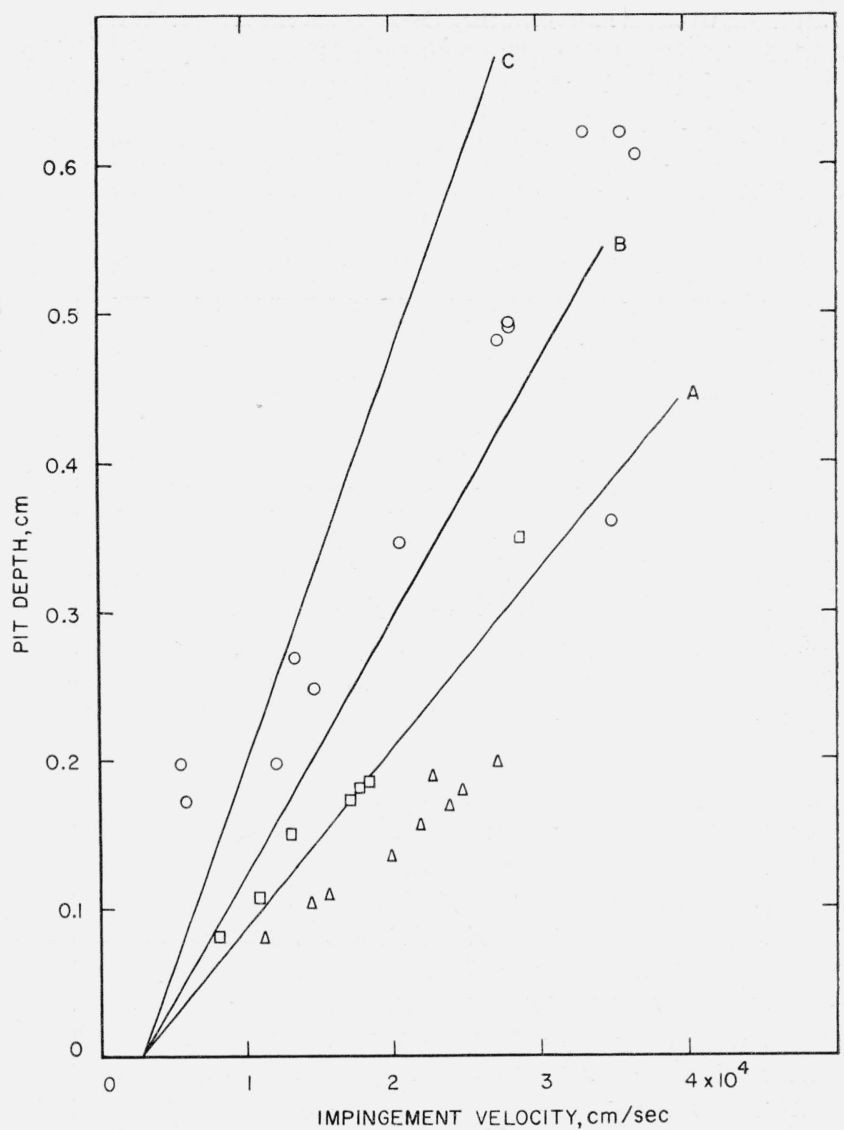

FIGURE \%. Collisions of steel spheres of three sizes against 2024-O aluminum.

Curve A, ealculated using eqs (3) and (4) for 0.5556-cm (7/32-in.) spheres; $\triangle$, observed depth produced by collision with $0.5556-\mathrm{cm}(7 / 32-\mathrm{in}$.) spheres $\triangle$, observed depth produced by collision with $0.5556-\mathrm{cm}(7 / 32-\mathrm{in}$.) spheres; $\checkmark$, observed depth produced by collision with $0.7938-\mathrm{cm}(5 / 16$-in.) spheres;

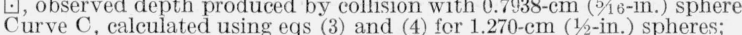
Curve C, calculated using eqs (3) and (4) for $1.270-\mathrm{cm}(1 / 2-\mathrm{in}$.) spheres;
$\odot$, observed depth produced by collision with $1.270-\mathrm{cm}(1 / 2-\mathrm{in}$.) spheres.

eter measured through the impact area of the sphere that was shot into $2024-\mathrm{O}$ aluminum was $0.00020 \mathrm{~cm}$ $(0.00008$ in.) smaller than diameters measured outside of the impact area. On the basis of this evidence it cannot be concluded that a larger percentage of the impact energy is absorbed by a steel sphere on colliding with 2024-O aluminum than on colliding with annealed copper. In fact, the reverse is the case. Deformation of the steel sphere is not the cause of the divergence of the 2024-O aluminum experimental pit-depth-versus-velocity data from the theoretical curves.

Cross-sectional cuts of the pits produced by these spheres were mounted in epoxy plastic in the NBS Mechanical Metallurgy Section (see fig. 8). They were given a high polish and examined with a microscope for evidence of crack formation. No evidence of crack formation was found. The cross section of the pit in 2024-O aluminum was then etched in an effort to accentuate any cracks if they existed, but no cracks were found. Crack formation in the tar- 


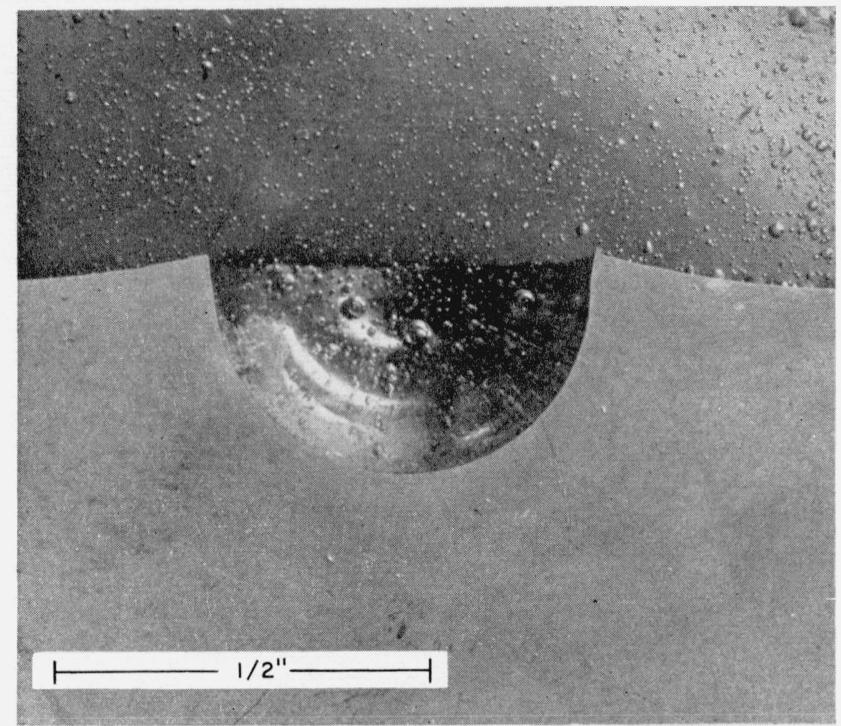

PIT IN ALUMINUM ALLOY

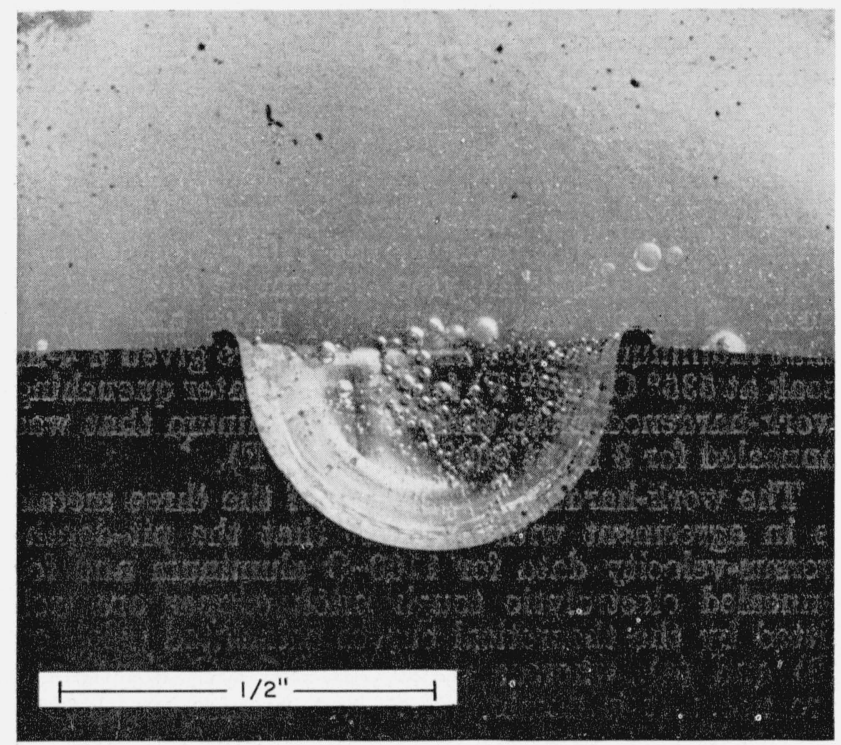

PIT IN COPPER

Figure 8. Cross sections of pits produced by collision of a $1.270-\mathrm{cm}(1 / 2-i n$.$) steel sphere with annealed electrolytic tough$ pitch copper and with 2024-O aluminum.

get is, therefore, not the cause of the divergence of the 2024-O aluminum experimental pit-depth-versusvelocity data from the theoretical curves.

It was then thought that the compressional wave caused by the collision may have reflected as a tension wave from the free reverse surface of the 2024-O aluminum target plate and may have returned to the collision surface with the effect of filling in the pits. This possibility is in agreement with the fact that attenuation of sound is greater in 1100-O aluminum and in annealed copper than it is in 2024-O aluminum.
To test this possibility a $1.59-\mathrm{cm}-(5 / 8-i n .-)$ thick plate of 1100 aluminum was cut to fit one of the 2.5-cm (1-in.-) thick target plates of 2024-O aluminum and was annealed under the same conditions as those that were used for the 1100-O aluminum targets. The contact surfaces between the two plates were machine ground and polished until, when they were pressed together, one plate was able to lift the other. They were tightly clamped together and 11 test firings were made against the combination target plate. The reverse (1100-O aluminum) face of the combination target plate was maintained as a free surface during the firings. Steel spheres $0.7938 \mathrm{~cm}(5 / 16 \mathrm{in}$.) in diameter were used for the shots.

It was hoped that if the compressional waves produced by the collisions had been returning to the collision surface as tension waves, they would now be prevented from doing this by attenuation on transit through the $1100-\mathrm{O}$ aluminum. However, when the measured pit depths were plotted against the impingement velocity, it was found that the points were in complete agreement with those obtained without the 1100-O aluminum backing plate. The pit-depth-versus-velocity data are given in table 10. Apparently the return of the reflected tension wave to the collision surface is unable to explain the divergence of the 2024-O aluminum pit-depth-versus-velocity data from the theoretical curves. It is possible, however, that the degree of contact that was attained between the 2024-O aluminum target plate and $1100-\mathrm{O}$ aluminum backing plate may not have been sufficient to ensure transmission of the elastic waves.

TABLE 10. Experimental data a for collisions of 5/16-in. steel spheres with a 2024-O aluminum and 1100-O aluminum combination target

\begin{tabular}{|c|c|}
\hline $\begin{array}{l}\text { Collision } \\
\text { velocity }\end{array}$ & Pit depth \\
\hline $\begin{array}{c}10^{4} \mathrm{~cm} / \mathrm{sec} \\
0.9601 \\
1.261 \\
1.478 \\
1.646 \\
1.890\end{array}$ & $\begin{array}{r}\mathrm{cm} \\
0.09_{6} \\
.12_{0} \\
.14_{9} \\
.16_{6} \\
.19_{3}\end{array}$ \\
\hline $\begin{array}{l}2.103 \\
2.603 \\
2.734 \\
2.841 \\
3.203 \\
3.755\end{array}$ & $\begin{array}{l}.22_{2} \\
.28_{0} \\
.29_{7} \\
.29_{4} \\
.36_{6} \\
.45_{3}\end{array}$ \\
\hline
\end{tabular}

a These data were obtained at the U.S. Naval Research Laboratory, Washington, D.C.

The explanation was finally sought in the workhardening properties of the three target metals. When a rigid sphere impinges against a metal target plate, shear stresses exist around the cylinder of target metal that is set in motion as a result of the collision, as indicated by the arrows marked $\tau_{A}$ in figure 9. Shear stresses also exist in the target metal around the point of impingement as indicated by the arrows marked $\tau_{B}$ in figure 9 . It seems reason- 


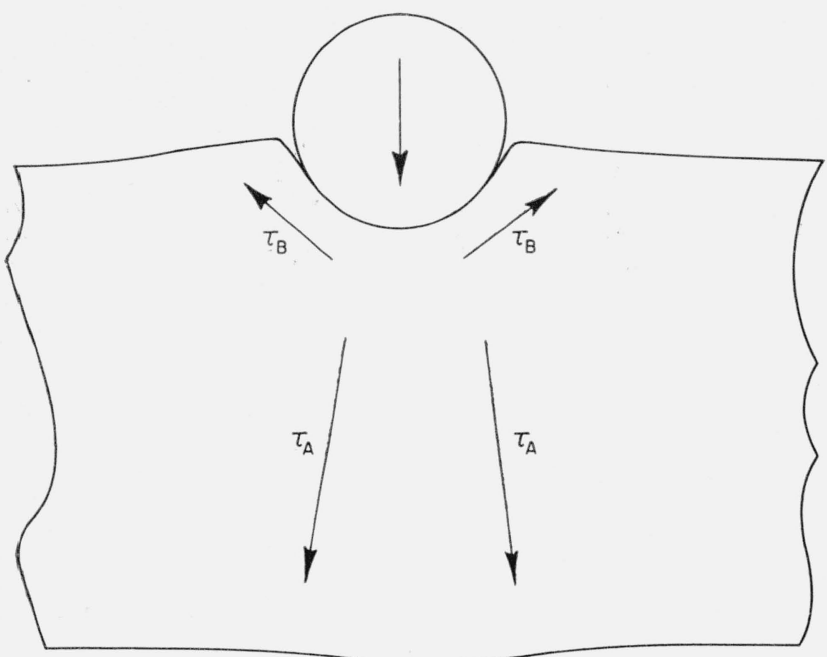

Figure 9. Shear stresses produced in a metal plate by an impinging steel sphere.

able that, if the metal does not work-harden readily, or if the $\tau_{B}$-shear stress is small, most of the plastic flow that takes place will occur as a result of the shear stress $\tau_{A}$ that exists below the collision area. If, however, the metal work-hardens extensively while this process is initiated, then flow as a result of the shear stress $\tau_{A}$ will be inhibited. In this case flow will occur as a result of the shear stress $\tau_{B}$, if the $\tau_{B}$-shear stress is appreciable, and the surface of the metal will be raised in a ring around the mouth of the pit that forms as a result of the collision.

It can be seen by laying a straight edge across the mouths of the crater cross sections shown in figure 8 that there is a considerable elevation of the target metal around the crater in the case of the 2024-O aluminum. Visual inspection of the target plates revealed that there was some rising of metal around the craters, especially in the case of the largest sphere size, for each of the target metals used. It appeared, however, to have occurred to a somewhat greater degree in the case of the 2024-O aluminum than in the case of the $1100-\mathrm{O}$ aluminum or of the annealed electrolytic tough pitch copper.

Equations (1), (2), (3), and (4) were developed on the assumption that the principal movement that occurs as a result of a liquid-drop or of a steel-sphere collision with a metal target plate is that of the core of metal under the collision area [1]. If any other flow process (such as that resulting from the shear stress $\tau_{B}$ ) becomes appreciable in a specific target metal, these equations cannot be expected to apply to pits formed in that metal.

The tensile stress-strain curves (fig. 10) provide a means of comparing the work-hardening properties of the 1100-O aluminum, annealed electrolytic tough pitch copper, and 2024-O aluminum used in the collision experiments. Work-hardening of metals

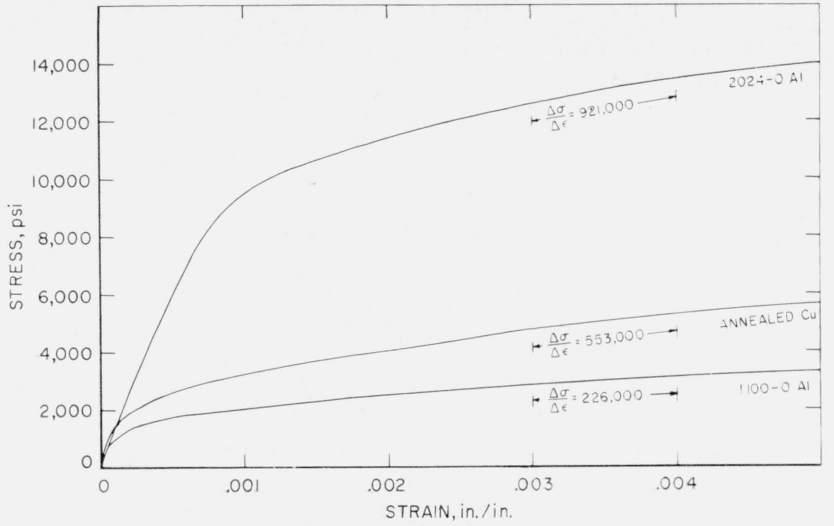

FIgURE 10. Stress-strain curves for 1100-O aluminum, 2024-O aluminum, and annealed electrolytic tough pitch copper.

may be evaluated by the tangent modulus [4]. The tangent moduli for the three metals in the range of strain from 0.003 to 0.004 are $1.56 \times 10^{10} \mathrm{~d} / \mathrm{cm}^{2}$ $(226,000 \mathrm{psi}), 3.81 \times 10^{10} \mathrm{~d} / \mathrm{cm}^{2}(553,000 \mathrm{psi})$, and $6.35 \times 10^{10} \mathrm{~d} / \mathrm{cm}^{2}(921,000 \mathrm{psi})$, respectively. These data suggest that the $2024-\mathrm{O}$ aluminum workhardens much more than does the annealed electrolytic tough pitch copper or the 1100-O aluminum. Copper is the main alloying element in 2024 aluminum. Thomas and Nutting [5] have also found that aluminum-copper alloys that were given a $4-\mathrm{hr}$ soak at $535^{\circ} \mathrm{C}\left(995^{\circ} \mathrm{F}\right)$ followed by water quenching work-hardened more than pure aluminum that was annealed for $3 \mathrm{hr}$ at $600^{\circ} \mathrm{C}\left(1,112^{\circ} \mathrm{F}\right)$.

The work-hardening behavior of the three metals is in agreement with the fact that the pit-depthversus-velocity data for 1100-O aluminum and for annealed electrolytic tough pitch copper are well fitted by the theoretical curves calculated using eq (3) and (4), whereas those for 2024-O aluminum are not. It is possible that the plastic yield that occurs in 1100-O aluminum and in annealed electrolytic tough pitch copper as a result of impingement of steel spheres may be caused almost entirely by the shear stress $\tau_{A}$, whereas the plastic yield that occurs in 2024-O aluminum as a result of impingement of steel spheres may be caused both by the shear stress $\tau_{A}$ and the shear stress $\tau_{B}$.

For mercury-drop and waterdrop impingement the pit-depth-versus-velocity data for 2024-O aluminum were well fitted by the theoretical curves calculated with use of eqs (1) and (2) (see fig. 2 and 4). This is not a contradiction because it is likely that the $\tau_{B}$-shear stress is smaller for the case of projectiles that flow during and as a result of the collision than for the case of projectiles that do not flow.

More data, using steel-sphere projectiles and target metals that have different work-hardening properties, are needed to prove whether or not this explanation is correct. 


\subsection{Collisions of Steel Spheres With Target Plates of 2024-O Aluminum That Were Backed With a Heavy Steel Supporting Block}

It has been pointed out that eqs (1), (2), (3), and (4) only apply to the case in which the target plate has edge support during the firings; the reverse side of the target plate must be a free surface. This is because the model on which eqs (1), (2), (3), and (4) are based involves the movement of the core of target material under the collision area with respect to the remainder of the target plate [1]. If the target plate is backed by a heavy metal plate or block, the reverse face of the target plate is not a free surface, the core of material under the collision area is not free to move with respect to the remainder of the target plate, and eqs (1), (2), (3), and (4) do not apply.

Pit-depth-versus-velocity data were obtained for collisions of steel spheres of three sizes against 2.5$\mathrm{cm}$ (1-in.-) thick target plates of 2024-O aluminum backed with a 12.7-by-15.2-cm (5-by-6-in.) steel supporting block 7.6-cm (3-in.) thick. These data are of no value as far as substantiation of eqs (1), (2), (3), and (4) is concerned. They are presented to show how the pit-depth-versus-velocity curve differs for the two modes of support of the target plate during the firings. These data are listed in table 11 and are plotted in figure 11 where best-fit curves have been drawn through the data for each size of steel sphere used. It can be seen from figures 7 and 11 that when the reverse side of the target plate is a free surface, the pit-depth-versus-velocity curve is a straight line, but that when the reverse side of

TABLE 11. Experimental data a for collisions of steel spheres of three sizes with 2024-O aluminum backed with a steel supporting block

\begin{tabular}{|c|c|c|c|c|c|}
\hline \multicolumn{2}{|c|}{$\begin{array}{l}\text { Sphere diameter } \\
0.5556 \mathrm{~cm}(7 / 32 \mathrm{in.})\end{array}$} & \multicolumn{2}{|c|}{$\begin{array}{c}\text { Sphere diameter } \\
0.7938 \mathrm{~cm} \text { ( } 5 / 16 \mathrm{in} .)\end{array}$} & \multicolumn{2}{|c|}{$\begin{array}{l}\text { Sphere diameter } \\
1.270 \mathrm{~cm}(1 / 2 \mathrm{in} .)\end{array}$} \\
\hline Velocity & Pit depth & Velocity & Pit depth & Velocity & Pit depth \\
\hline $\begin{array}{r}10^{4} \mathrm{~cm} / \mathrm{sec} \\
1.106 \\
1.192 \\
1.295 \\
1.548 \\
1.844\end{array}$ & $\begin{array}{r}c m \\
0.74_{4} \\
.08_{0} \\
.08_{7} \\
.10_{6} \\
.12_{7}\end{array}$ & $\begin{array}{c}10^{4} \mathrm{~cm} / \mathrm{sec} \\
0.6035 \\
1.012 \\
1.186 \\
1.247 \\
1.356\end{array}$ & $\begin{array}{r}c m \\
0.09_{9} \\
.11_{5} \\
.14_{7} \\
.12_{1} \\
.11_{7}\end{array}$ & $\begin{array}{c}10^{4} \mathrm{~cm} / \mathrm{sec} \\
0.9753 \\
.9845 \\
1.341 \\
1.664 \\
1.966\end{array}$ & $\begin{array}{r}\mathrm{cm} \\
0.16_{0} \\
.16_{2} \\
.23_{0} \\
.28_{3} \\
.33_{2}\end{array}$ \\
\hline $\begin{array}{l}2.027 \\
2.115 \\
2.298 \\
2.408 \\
2.438\end{array}$ & $\begin{array}{l}.14_{1} \\
14_{6} \\
.16_{5} \\
.17_{4} \\
17_{9}\end{array}$ & $\begin{array}{l}\text { 1. } 369 \\
\text { 1. } 384 \\
\text { 1. } 384 \\
\text { 1. } 417 \\
1.436\end{array}$ & $\begin{array}{l}.13_{3} \\
.13_{5} \\
.13_{6} \\
.13_{3} \\
.14_{0}\end{array}$ & $\begin{array}{l}2.094 \\
2.143 \\
2.146 \\
2.502 \\
2.697\end{array}$ & $\begin{array}{l}.37_{0} \\
.37_{4} \\
.37_{5} \\
.43_{8} \\
.51_{2}\end{array}$ \\
\hline $\begin{array}{l}2.502 \\
2.609 \\
2.615 \\
2.615 \\
2.688\end{array}$ & $\begin{array}{l}.18_{2} \\
18_{7} \\
.19_{3} \\
.18_{8} \\
19_{8}\end{array}$ & $\begin{array}{l}1.481 \\
1.503 \\
1.622 \\
1.786 \\
1.823\end{array}$ & $\begin{array}{l}.139 \\
.14_{9} \\
.157 \\
.178 \\
.184\end{array}$ & $\begin{array}{l}\text { 2. } 780 \\
\text { 3. } 283 \\
4.331\end{array}$ & $\begin{array}{l}49_{5} \\
.61_{8} \\
.46_{1}\end{array}$ \\
\hline $\begin{array}{l}3.036 \\
3.216\end{array}$ & $\begin{array}{l}.23_{1} \\
.25_{2}\end{array}$ & $\begin{array}{l}\text { 1. } 939 \\
2.057 \\
2.216 \\
2.640 \\
3.255 \\
3.572 \\
4.209 \\
4.848\end{array}$ & $\begin{array}{l}.19_{7} \\
.21_{1} \\
.23_{0} \\
.28_{7} \\
.37_{2} \\
\\
.41_{6} \\
.52_{9} \\
.64_{6}\end{array}$ & & \\
\hline
\end{tabular}

a These data were obtained at the U.S. Naval Research Laboratory, Washington, D.C

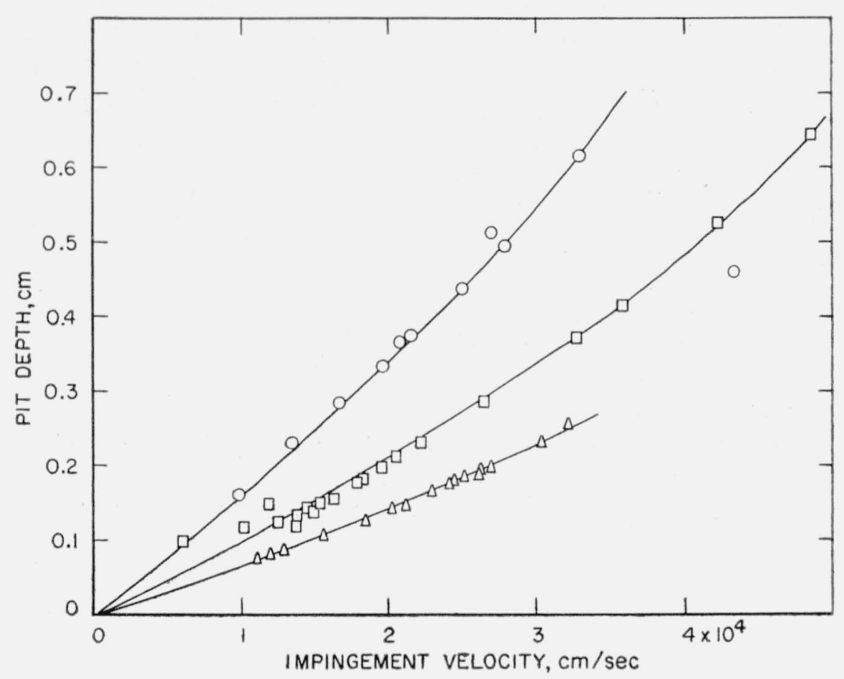

FIGURE 11. Best-fit curves for collisions of steel spheres against 2024-O aluminum targets backed with a heavy steel supporting block.

$\Delta$, observed depth produced by collision with $0.5556-\mathrm{cm}(7 / 32-i n$.) spheres; $\ulcorner$, observed depth produced by collision with $0.7938-\mathrm{cm}(5 / 16-\mathrm{in}$.) spheres $\odot$, observed depth produced by collision with $1.270-\mathrm{cm}(1 / 2-i n$.$) spheres.$

the target plate is not a free surface (use of a backing plate or block), the pit-depth-versus-velocity curve is not a straight line.

For the case that the reverse face of the target plate is a free surface, the projectile is stopped by resistance to the movement of the core of metal under the contact area. For the case that the reverse face of the target plate is not a free surface, the projectile is stopped by resistance to extrusion of metal around the crater.

\section{Liquid-Against-Liquid Collisions}

Very little study has been made of collisions that occur when liquid drops collide with a target liquid. It was postulated by Öpik [6] nearly 25 years ago, later by Pack and Evans [7], and recently by others [8] that at extremely high impingement velocities solid targets and projectiles will behave as though they were liquids. OOpik stated, "The 'aerodynamic' pressure at the penetration of a meteor into rock is of the order of $10^{7}-10^{8}$ atmospheres, or more than 1,000 times the plastic limit of steel; no doubt all solid materials under such pressures must behave like liquids; thus the problem of meteor impact is the case of the impact of a liquid drop of given density $\delta$ into a liquid medium of density $\rho . "$

It has been found that when solid-sphere projectiles made of the soft ductile metals are fired at sufficiently high impingement velocities against targets of the same metal, they flow like liquids during and as a result of the collision. Pit depth for such solid-against-solid collisions has been found [1] to be given by eqs (1) and (2) which apply to collisions of liquid drops against metal plates. 
If the impingement velocity is increased further, it is reasonable to suppose that the behavior predicted by Öpik [6] will eventually be found; the target as well as the projectile will liquefy during the collision. For such collisions that occur at meteor velocities Öpik [6] found that the impingement velocity has only a small effect upon the depth of penetration. If this is the case, the pit-depth-versusvelocity curve for such collisions should run almost parallel to the velocity axis. The penetration formula developed by Pack and Evans [7] has no velocity dependence.

It appears that the straight-line, low-velocity, liquid-against-solid, and solid-against-solid pitdepth-versus-velocity curves for collisions of liquid

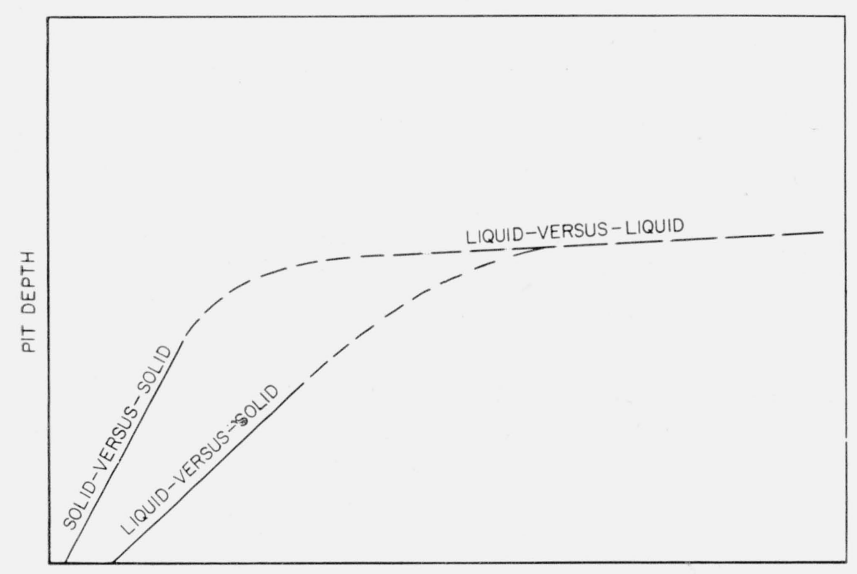

IMPINGEMENT VELOCITY

Figure 12. Schematic relation between various types of projectile-target collisions. drops and rigid steel spheres with metal plates must approach the high-speed liquid-against-liquid curve in some way when very high impingement velocities are reached. This is represented schematically in figure 12 where dashed lines have been used to indicate projected types of behavior.

Equations (1), (2), (3), and (4) will not apply either in the transition regions or in the velocity range of high-speed liquid-against-liquid collisions. An analysis of liquid-against-liquid collisions is in progress.

\section{References}

[1] Olive Engel, Pits in metals caused by collision with liquid drops and soft metal spheres, NBS Journal of Research 62, 229 (1959) RP2958.

[2] A. C. Whiffin, The use of flat-ended projectiles for determining dynamic yield stress, Proc. Roy Soc. (London) [A] 194, 300 (1948).

[3] L. Bergmann, Der Ultraschall, S. Hirzel Verlag, Stuttgart, 1954.

[4] John M. Lessells, Strength and resistance of metals (John Wiley and Sons, Inc., New York, N.Y., 1954).

[5] G. Thomas and J. Nutting, The plastic deformation of aluminum and aluminum alloys, J. Inst. Metals 85, 1 (1956).

[6] Ernst Öpik, Researches on the physical theory of meteor phenomena I, Toimetused, Acta et Commentationes, Universitatis Tartuensis, XXX, [A] 4 (1936) (Tartu, Estonia).

[7] D. C. Pack and W. M. Evans, Penetration of highvelocity ("Munroe") jets I and II, Proc. Phys. Soc. (London), LXIV B, 298, 303 (1951).

[8] See, for example, Proc. of Third Symposium on Hypervelocity Impact, Vol. I (Armour Research Foundation of Illinois Inst. Technol., Chicago, Ill., Feb., 1959).

Washington, D.C.

(Paper 64A1-29) 